\title{
Renal Biopsy in the Pediatric Patient
}

\author{
Isa F. Ashoor, Deborah R. Stein and Michael J. G. Somers \\ Division of Nephrology \\ Children's Hospital Boston \\ Harvard Medical School, Boston, Massachusetts \\ USA
}

\section{Introduction}

Renal biopsy in children can be performed either by percutaneous, laparoscopic, or open surgical approaches. As reported in a recent large pediatric series (Hussain et al., 2010), the percutaneous approach is by far the most commonly utilized, with the open approach typically reserved for situations in which percutaneous biopsy may be relatively contraindicated or there is the need for a large wedge of tissue. Increasingly, more centers are reporting successful experience with laparoscopic approaches as an alternative to open surgical biopsies (Caione et al., 2000; Luque Mialdea et al., 2006; Mukhtar et al., 2005).

Native renal biopsy should be performed in a child when kidney disease is suspected and treatment decisions require confirmation, when staging or characterization of a known kidney disease is warranted, or when the disease diagnosis is known but the utility of further treatment is questioned. In contrast to adults, renal insufficiency in children is more often secondary to sequelae from congenital or structural anomalies rather than acquired diseases. As a result, loss of renal function is not unexpected and tends to progress more slowly. Typically, children with such well-defined renal anomalies do not undergo biopsy even as renal function declines, unless a new entity is thought to be present.

On the other hand, children presenting with an acquired kidney condition, especially with rapidly changing renal function or lack of response to empiric therapy, do require renal biopsy to allow for accurate diagnosis and tailoring of therapeutic intervention. Moreover, while relatively common medical conditions such as hypertension and diabetes mediate much of the chronic kidney disease seen in adults, these conditions are rarer in children and less likely to impact renal health in the pediatric patient, leading to a need for clinicians to actually identify why kidney disease has arisen in the child.

In contrast to many adults, children and adolescents typically require significant conscious sedation or even general anesthesia for successful renal biopsy. Consequently, the risks of both the procedure and sedation/anesthesia must be considered when determining whether to do the biopsy. There are several medical conditions that often preclude biopsy. Although each case must be individually considered and there may be an occasion when the information garnered at biopsy outweighs the potential risk, the following situations are often considered contraindications or relative contraindications for pediatric biopsy: 
Contraindications for biopsy:

- $\quad$ Severe bleeding disorders such as hemophilia

- Known abdominal malignancy

- Multiple renal cysts or renal tumor preventing sampling of renal parenchyma

- Compromised skin or skin infection overlying biopsy entry site

- Uncontrolled hypertension, increasing the risk of post-operative bleeding

Relative Contraindications:

- Massive ascites

- Severe hydronephrosis

While some have challenged the safety of performing renal biopsy in a child with a solitary kidney, current complication rates have decreased to such a degree that, if warranted for diagnostic reasons and if being performed by experienced clinicians utilizing medical imaging to visualize the kidney during biopsy, this is generally not considered to be a contraindication.

\section{Nuts and bolts: Logistics of planning and preparation for the biopsy procedure}

If no ultrasound has been obtained in the past or if there is concern that there may have been an interval change in the kidney or urinary tract anatomy since the last imaging study, a renal ultrasound is performed to assess for anomalies such as hydronephrosis, to confirm location and number of kidneys, and to assess renal size prior to the biopsy. The point of the ultrasound is to identify any anatomic reason why biopsy would be contraindicated or that would alter the approach to the biopsy.

A complete blood count (CBC), coagulation panel including prothrombin time (PT) and partial thromboplastin time (PTT), as well as a sample for type and screen to be held in the blood bank are obtained, typically within 72 hours of the procedure. The CBC allows baseline hematologic parameters to be ascertained in case there is concern regarding bleeding or infection post-procedure and also confirms an acceptable platelet count prior to an invasive procedure. The PT/PTT identifies any tendency toward a coagulopathy that may increase the chances of a bleeding complication. Although transfusion post-biopsy is rare, having a blood type and screen in the blood bank will expedite this process if it is necessary, and especially if it is urgently required.

Informed consent is obtained from either the parent/guardian or the patient if the patient is of legal age. The consent process must include explaining the risks of the procedure, however rare, including bleeding, infection, and the potential need for surgery to control bleeding or perform nephrectomy. In children less than 18 years of age who are cognitively capable of understanding the rationale for the biopsy procedure, in addition to informed consent from the parent or legal guardian, there is utility in obtaining assent from the child. This documents that the patient was also involved in the decision to proceed with the biopsy and underscores the need to keep the patient involved in a developmentally appropriate fashion with the process.

Prior to the biopsy, the patient will need to fast for some period of time, depending on whether sedation or anesthesia is being utilized and institutional protocols. Most children should tolerate this period of time without the need for supplemental intravenous hydration, but individual circumstance and clinical status must be reviewed to determine if the usual period of fasting is likely to cause any untoward consequence; for instance, a child 
with diabetes insipidus or a child with a severe urinary concentrating defect would require special hydration plans.

\section{Nuts and bolts: Sedation or anesthesia for the pediatric renal biopsy}

Local standards and individual clinician preference have the greatest impact on the type of sedation or anesthesia for pediatric patients undergoing percutaneous renal biopsy. The overwhelming majority of children are offered intravenous conscious sedation or some sort of general anesthesia, with very few patients declining such measures and opting for local anesthesia injected at the biopsy site alone. In rare cases of children with serious contraindication or objection to sedation or anesthesia, "verbal sedation" has been used, with the child talked through the procedure with the help of a child life specialist trained in this approach (Hussain et al., 2003).

Case series from North American centers show that general anesthesia is most often reserved for infants or very small children where lack of cooperation during the procedure is a concern as well as in children whose airways may be at risk with sedation alone (Birk et al., 2007; Simckes et al., 2000; Sweeney et al., 2006). This approach is not necessarily the case worldwide and, in fact, a recent audit in the United Kingdom (Hussain et al., 2010) showed 6 of 11 centers routinely using general anesthesia for pediatric kidney biopsies.

Intravenous "conscious" sedation, sometimes termed "deep" procedural sedation, is usually administered by a nurse or physician who has acquired expertise in various sedation techniques and certification in pediatric advanced life support (Cravero et al., 2006; Mason et al., 2009). The patients should receive continuous cardiorespiratory monitoring throughout the procedure. A variety of agents may be utilized and the protocols are institution specific or dependent on local resources.

Our institution has successfully employed a radiologist-supervised ketamine sedation protocol for many solid organ biopsies (Mason et al., 2009). In this protocol, children receive an IV Ketamine bolus $(2 \mathrm{mg} / \mathrm{kg}$ ) over a 5-minute period with concomitant administration of 0.005 $\mathrm{mg} / \mathrm{kg}$ of IV glycopyrolate. The bolus of ketamine is immediately followed by a continuous infusion of $25-150 \mathrm{mcg} / \mathrm{kg} / \mathrm{min}$ of ketamine for the duration of the procedure. Patients older than 5 years also receive $0.1 \mathrm{mg} / \mathrm{kg}$ of midazolam hydrochloride (maximum $=3 \mathrm{mg}$ ) before the initial bolus of ketamine. There have been no major adverse events reported with this protocol and both patient and family satisfaction rates have been high.

Other published sedation protocols employ a combination of meperidine $(1 \mathrm{mg} / \mathrm{kg}-$ maximum $50 \mathrm{mg}$ ) and diazepam $(0.2-0.4 \mathrm{mg} / \mathrm{kg})$, with ketamine reserved for additional sedation if necessary (Hussain et al., 2003); midazolam $0.1 \mathrm{mg} / \mathrm{kg}$ with additional ketmaine where required (Mahajan et al., 2010); or intravenous propofol $(1 \mathrm{mg} / \mathrm{kg} /$ dose titrated to effect) and fentanyl (1 $\mu \mathrm{g} / \mathrm{kg} /$ dose) (Birk et al., 2007). Again, local practice and clinician familiarity and expertise with certain medications tend to influence the type of sedation provided most successfully and is more critical than the use of any specific medication or combination of medications.

Local anesthesia may be achieved by applying a topical anesthetic cream (EMLA, lidocaine $2.5 \%$ and pritocaine $2.5 \%$ or Ametop tetracaine $4 \%$ ) (Hussain et al., 2003) or local infiltration with $1 \%$ lidocaine. At our center, for local infiltration with lidocaine, $9 \mathrm{mls}$ of lidocaine are mixed with $1 \mathrm{ml}$ of $8.4 \%$ sodium bicarbonate; this approach seems to decrease complaints of burning at the site of infiltration, and this is employed regardless of the type of sedation utilized. 
The majority of percutaneous renal biopsies performed under sedation are done outside the operating room, usually in an interventional radiology suite, a procedure area with access to ultrasound imaging, or in ward treatment rooms (Davis et al., 1998; Hussain et al., 2003; Mason et al., 2009). Although there were initial concerns about providing sedation in such settings for invasive procedures, our own experience and that of others have shown few safety concerns. The Pediatric Sedation Research Consortium reported a large series of 30,037 sedation encounters from 26 centers, with data submitted on a variety of pediatric procedures performed under sedation or anesthesia outside the operating room (Cravero et al., 2006). This study demonstrated the overall safety of such procedures, with no deaths and only one cardiopulmonary resuscitation event. The most commonly encountered adverse event in this cohort was more than 30 seconds of oxygen desaturation to less than $90 \%$ by transcutaneous monitoring, and this only occurred in $1.5 \%$ of cases. Needless to say, the safety and success of such programs depend on consistently following well-developed protocols, the presence of certified providers throughout the procedure, and readily available anesthesia services to handle unexpected complications.

\section{Nuts and bolts: Performing the renal biopsy}

As discussed above, institutional practice and resources often guide the location for pediatric biopsies. For instance, in our center, biopsies are performed in an Interventional Radiology suite with either nurses providing conscious sedation by protocol or Pediatric Anesthesiologists providing general anesthesia. The use of sedation versus anesthesia typically depends on the age of the patient, developmental and emotional factors, and any co-morbid medical conditions. For instance, a very young child with nephrotic syndrome and significant volume overload will likely warrant general anesthesia whereas a mature adolescent undergoing a transplant biopsy may need little other than local anesthesia over the biopsy site.

Biopsies are performed under sterile conditions. As a result, it is important for the individual performing the biopsy to follow standard protocol for a sterile invasive procedure including aseptic technique and wearing appropriate gowns, gloves, masks, and eye protection.

Obtaining an adequate sample is crucial for any renal biopsy, but is even more imperative in children undergoing biopsy where the logistics of the procedure may be more complicated. Availability of a dissecting microscope to view each core obtained to assess tissue adequacy is extremely useful to guide the number of cores needed. Presence of either a pathologist or nephrologist experienced in identifying renal tissue under dissecting microscope is obviously essential and should allow some estimation of tissue adequacy.

For a native renal biopsy, the child is placed in a prone position and typically the left kidney is imaged to discern an acceptable biopsy site. In a transplant patient, the child will be supine and the area immediately over the allograft is imaged. The skin overlying the area most appropriate for biopsy needle introduction is marked during this process. Generally, a site in the lower pole of the kidney is selected, away from the renal hilum and large vessels. At this point, prior to proceeding further with the procedure, a pause or "time-out" is worthwhile, with the individual performing the procedure reviewing aloud the patient's name, medical diagnosis, planned procedure including site of biopsy, and confirming that informed consent has been obtained. All others in the procedure area should then verbally identify themselves and their role in the procedure, for instance "Jane Jones, RN performing 
sedation" or "John Smith, attending radiologist" so that there is both acknowledged consensus of the procedure to be done by all involved and understanding of the specific roles of all the individuals present in the area.

The biopsy area is cleaned thoroughly with a betadine solution, and all areas outside the sterile field are covered with sterile drapes. A local anesthetic such as lidocaine is injected at the marked skin site. An initial wheal is made and then deeper infiltration performed, following the anticipated path of the biopsy needle. A superficial dermatotomy is made over the wheal, and the biopsy needle is advanced through this area.

Typically, most pediatric renal biopsies are now done with ultrasound guidance. If desired, this allows use of a needle guide that helps to position the path of the biopsy needle along the desired biopsy tract. It also allows for continuous monitoring of the position of the needle during the procedure and allows for ready identification of structures such as bowel or large vessels that must be avoided. Optimally, the individual performing the biopsy has been trained in biopsy sonography as well, so that the same individual is controlling the imaging and the needle placement; otherwise, there needs to be continuous communication between the individual advancing the biopsy needle and the sonographer to be sure that both agree as to the needle position and the target.

Local practice and available resources will determine the biopsy devices and needles used, most of which are readily available from medical vendors. For most percutaneous pediatric renal biopsies at our center, we use an 18-gauge needle and an automated biopsy device or "gun" that is loaded with the needle. The desired "throw" -- or length of the biopsy needle that gets propelled into the kidney when the device is engaged -- depends on the size of the child and the size of the kidney being biopsied. For most children, a throw of approximately 2 centimeters allows for a safe biopsy with sufficient tissue but, in especially young children or with small kidneys, a shorter throw may be needed to avoid the renal hilum or other surrounding structures.

The needle is advanced to the selected site in the lower pole renal cortex under continuous ultrasound guidance. Once the needle reaches the renal capsule, it is advanced slightly further to enter kidney tissue. The biopsy device is then "fired" which allows the inner hollow-core biopsy needle to deploy, cutting a piece of kidney tissue. The cutting needle is then automatically ensheathed by an outer protective core. The entire biopsy needle device is withdrawn from the kidney and the protective sheath withdrawn to expose the tissue core. The biopsy sample is carefully transferred onto a saline-soaked gauze by rolling the needle onto the gauze, and then the core is examined by the pathologist or nephrologist under a dissecting microscope for quick estimation of tissue adequacy. During this time following needle extraction, the physician performing the biopsy or another designee applies pressure to the biopsy site.

This procedure is repeated until adequate renal tissue has been obtained for the biopsy indication, depending on the patient's medical condition and the studies to be performed on the tissue. Typically, for native kidney biopsies, we obtain three cores of tissue to allow for sufficient tissue for light microscopy, immunofluorescence, and electron microscopy. For transplant biopsies, two cores are generally obtained since fewer studies are usually done. As always, the size and adequacy of tissue cores obtained will specifically define the number of cores needed for any patient. If adequate tissue is not obtained after three to five passes of the needle, then there must be consideration of the risk of ongoing passes into the kidney versus the benefits of obtaining more kidney tissue at this point in time. 
At completion of the entire biopsy procedure, pressure is applied externally over the biopsy site for a minimum of 5 minutes. A post-biopsy ultrasound with Doppler imaging is then performed to evaluate for any hematoma or active bleeding. If bleeding is observed, pressure is maintained until there is evidence of stable imaging with no expanding hematoma or determination is made that there needs to be some other intervention. The dermatotomy site is covered with a sterile dressing that may be removed the following day. This dressing is observed for any bleeding or drainage while it is in place.

\section{Open renal biopsy in children}

Rarely, an open renal biopsy is appropriate in children. Common indications for open renal biopsy are listed in Table One. Some clinical scenarios where open biopsy is more common include when attempts at a percutaneous biopsy have failed, when a wedge resection is required for pathologic diagnosis, or when there is a bleeding disorder but the biopsy is paramount to treatment decisions. Open biopsy is performed typically by a general surgeon, urologist, or transplant surgeon in an operating room. Open renal biopsy will usually result in exposure to general anesthesia or more prolonged sedation with longer post-procedure recovery times, hence increasing health care delivery costs.

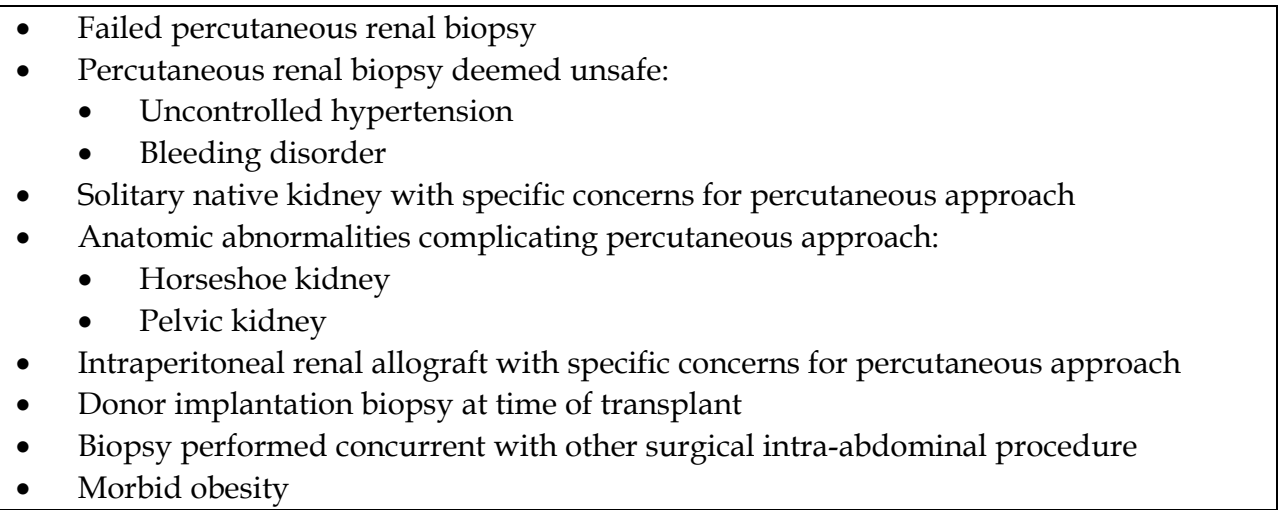

Table 1. Common Indications for Open Renal Biopsy

There may be center-specific variation in the use of open biopsy depending on local experience and expertise. Similarly, there may be changes in local practice regarding specific clinical scenarios that may come to decrease the need for open renal biopsy. For instance, several centers have published their experiences transitioning from open to percutaneous biopsies of solitary kidneys and transperitoneal allografts (Mendelssohn \& Cole, 1995; Vidhun et al., 2003). In cases that may be considered higher risk for percutaneous approach, most clinicians think it judicious to pay special attention to coagulation parameters, blood pressures and serum creatinine in determining the optimal approach for renal biopsy (Davis et al., 1998; Simckes et al., 2000). Similarly, in situations where a clinician is performing a higher risk percutaneous biopsy, it would be warranted to ensure in advance that there is availability of interventional radiology or surgical support services for unexpected complications. 


\section{Laparoscopic renal biopsy}

Within the last decade, there has also been increased utilization of laparoscopic approach as an alternative to traditional open biopsy. This approach has been well-established in morbidly obese adults where the body habitus precludes percutaneous approach (Mukhtar et al., 2005, as cited in Shetye et al., 2003). Unfortunately, obesity rates in children are at an all-time high and show no signs of abating (Anderson \& Whitaker, 2009; Broyles et al., 2010). Obesity is also a frequent complication of steroid therapy commonly used in treating various glomerular lesions and in maintenance immunosuppression for renal transplant recipients who may come to require biopsy. Furthermore, in the face of the obesity epidemic, we are increasingly recognizing the entity of obesity-related secondary focal segmental glomerulosclerosis presenting with heavy proteinuria (Fowler et al., 2009). Consequently clinicians may find an increasing population of obese children requiring biopsy whose body habitus prevents a percutaneous approach.

Mukhtar et al (Mukhtar et al., 2005) reported their experience with two morbidly obese children where initial attempts at percutaneous biopsy failed. The procedures were then carried out laparoscopically with no major complications, and both children were discharged home within 48 hours at significant cost savings compared to an open biopsy. Two larger case series from Italy and Spain (Caione et al., 2000; Luque Mialdea et al., 2006) also described successful experiences with laparoscopic renal biopsies in 20 and 53 pediatric patients, respectively. Children in those series ranged in age from 13 months to 19 years. The procedure was safe and successful in all but one patient in each series who required conversion to an open biopsy. The mean hospital stay in both cohorts was 48 hours or less.

\section{Differences between native and transplant biopsies in children}

In most children $>20 \mathrm{~kg}$, transplanted kidneys are typically placed extraperitoneally in the lower abdomen within the iliac fossa. In smaller children, kidneys may need to be placed intraperitoneally. In most pediatric renal transplant recipients, transplanted kidneys are far more superficial than native kidneys and this must be kept in mind during biopsy to avoid improper sampling or damage to the vascular structures. Again, ultrasound guidance during the biopsy procedure will help to minimize these technical complications. In those children with intraperitoneal allografts, care must be taken to avoid bowel or other structures that may overlie the allograft.

Allograft biopsies are typically performed to evaluate for acute rejection, to assess for recurrence of diseases such as Focal Segmental Glomerulosclerosis (FSGS), to define new onset suspected glomerular disease, to assess extent of chronic allograft nephropathy, or to document infectious insults such as BK virus nephropathy. Some centers may perform interval "protocol" biopsies at set intervals to assess the allograft parenchyma. Processing and staining of the biopsy samples from transplanted kidneys depends on the biopsy indication (see section 10).

\section{Post-biopsy monitoring in children}

There are currently no standard guidelines established for post renal biopsy monitoring. The standard of care in adult patients has included bed rest with close observation for up to 24 hours (Whittier \& Korbet, 2004). In their retrospective analysis of 750 adult patients who underwent native renal biopsy, Whittier and Korbet found an observation time of up to 24 
hours to be optimal, with an observation period of 8 hours or less missing up to $33 \%$ of complications. There are, however, various clinical and social factors that impact any specific patient's circumstances and, as a result, the length of observation post-biopsy should be somewhat individualized.

In children, there are also wide variations in practice for post-biopsy monitoring. For instance, a survey of pediatric nephrologists in Japan (Kamitsuji et al., 1999) covering complications in 2,045 native percutaneous renal biopsies revealed that no center allowed discharge within 24 hours of the biopsy, with $67 \%$ of patients remaining in the hospital for at least 4-8 days. The patients in this cohort had similar complication rates to other pediatric series with shorter duration of observation, however, and the prolonged hospital stay was attributed to local practice.

Over the last two decades, with increasing safety of percutaneous renal biopsy, particularly when performed with an automated biopsy needle under real time ultrasound guidance, more centers are moving towards short post-biopsy monitoring times for both native and allograft renal biopsies in children. In fact, several centers in North America and Europe have implemented same day renal biopsy in ambulatory or day clinical care units as standard practice for low risk patients since the early 1990s (Birk et al., 2007; Hussain et al., 2003; Sweeney et al., 2006). This trend has been associated with significant cost savings compared to inpatient renal biopsies and comparable safety outcomes (Chesney et al., 1996; Hussain et al., 2003; Lau et al., 2009; Simckes et al., 2000). In addition, several centers in developing countries are reporting successful experiences with percutaneous renal biopsies in the ambulatory setting, where it was initially promoted for logistical reasons associated with limited inpatient bed space (Al Makdama \& Al-Akash et al, 2006; Mahajan et al., 2010). In most centers where pediatric renal biopsies are performed as an inpatient procedure, there is consensus regarding the utility of bed rest in the supine position for a period of 3-6 hours post biopsy. Patients are asked to save their urine for gross inspection and most centers allow the patient to stand to void if two consecutive post-biopsy urine samples are negative for gross hematuria. Vital signs are usually monitored every 15-30 minutes in the first 2 hours post biopsy and less frequently thereafter. Some centers provide intravenous hydration until patients are fully awake and able to drink. Most centers utilize acetaminophen for analgesia.

Local standards often dictate post biopsy laboratory investigations or imaging studies. In our institution, biopsies are performed by nephrologists trained in renal sonography in the presence of an interventional radiologist who can immediately assist if there is some question or concern for an adverse event. As noted above, immediate post-biopsy images are also obtained by ultrasound to assess for hematoma formation and to provide a postbiopsy baseline. Others employ routine post-biopsy ultrasound from 24 hours to two weeks following renal biopsy in all patients to detect peri/intra renal hematoma formation with consideration of Doppler studies to assess for arteriovenous fistula formation (Al Rasheed et al., 1990; Kamitsuji et al., 1999; Mahajan et al., 2010), though it is unclear whether this changes clinical care of the stable patient (Castoldi et al., 1994).

It is also our practice to observe patients for at least 6 to 8 hours post-procedure and to check a hemoglobin and hematocrit level at 4-6 hours post biopsy and again the next morning as long as there is no concern to warrant repeat laboratory work sooner. A hematocrit drop of greater than $5-7 \%$, severe abdominal or flank pain, gross hematuria that does not clear or markedly improve within two to three voids, or any evidence of hemodynamic instability 
would prompt urgent renal imaging with an ultrasound to detect ongoing bleeding or expanding hematoma formation.

In those centers that perform percutaneous renal biopsies in the ambulatory setting without provision for hospital admission, the selection criteria for low risk patients generally include normal or controlled blood pressure, normal pre-biopsy hematocrit and coagulation studies, a competent care giver to monitor the patient after the procedure, and the family's willingness to stay within a reasonable distance of the hospital for the first night post-biopsy (Ogborn \& Grimm, 1992). Following the biopsy, patients are typically monitored for 6-8 hours with strict bed rest for 1-3 hours. Patients are discharged home at the end of this observation period if their urine is free of gross hematuria, their vital signs are stable and they have no significant pain at the biopsy site (Birk et al., 2007; Hussain et al., 2003; Ogborn \& Grimm, 1992; Simckes et al., 2000).

The value of routine post-biopsy imaging studies is controversial, with several studies suggesting the development of post biopsy perinephric hematomas is common and does not negatively impact patient outcomes or change the need for patient care in most cases (Castoldi et al., 1994; Vidhun et al., 2003). Detection of hematoma may also be a function of sensitivity of the imaging technique employed. For instance, data from CT scanning post biopsy reveals that perinephric hematoma is almost universal (Castoldi et al., 1994, as cited in Ralls et al., 1987). Castoldi et al further attempted to stratify hematomas according to size and correlate them with patient outcomes. In their retrospective analysis of 230 patients where 218 underwent post-biopsy sonography within 72 hours, the incidence of parenchymal, subcapsular, and perinephric hematomas combined was $42 \%$. In the absence of clinical signs of bleeding, no short or long-term adverse effects were reported and, even in the presence of clinical signs of bleeding, serious complications only occurred in those with large hematomas. Large hematomas were defined as those having a thickness greater than $1 \mathrm{~cm}$ and length greater than $3 \mathrm{~cm}$. Moreover, although these large hematomas were found in 20 patients ( $9 \%$ of their total cohort), only 7 of these patients had more than a $7 \%$ decrease in their post-biopsy hematocrit values. On the other hand, all hematomas with a thickness less than $2 \mathrm{~cm}$ in their study had a favorable clinical course.

Davis et al (Davis et al., 1998) evaluated the utility of monitoring the post-biopsy change in hemoglobin concentration to identify bleeding complications that were otherwise not clinically apparent. In their retrospective review of 177 percutaneous renal biopsies (137 native, 40 transplant), hemoglobin measurements were obtained at 4-10 hours and 15-24 hours post biopsy. In their study, using a drop in hemoglobin levels of more than $16 \%$ of baseline - for instance from $10 \mathrm{~g} / \mathrm{dl}$ to $8.4 \mathrm{~g} / \mathrm{dl}$-- served as a sensitive (100\%) and specific $(98 \%)$ marker of major bleeding complication that required either transfusion or additional monitoring. The change in post-biopsy hemoglobin was not associated with the presence of gross hematuria or perinephric hematoma, which were considered minor complications in this study.

Children are allowed to return to school within one to two days of biopsy, though participation in physical education classes is usually avoided for one week. Children are also encouraged to avoid contact sports or vigorous activities that might result in direct trauma to the biopsy site for one week. Children are allowed to shower but immersion of the biopsy site in water is not recommended until the dermatotomy site is scabbed over, which typically occurs within 48 to 72 hours. In the immediate post-biopsy period, families are instructed to contact their pediatric nephrologist urgently for new onset gross hematuria, dysuria, pain at the biopsy site, or fever. 


\section{Complications post-biopsy}

Percutaneous renal biopsy as performed in most pediatric centers today with ultrasound guidance and automated biopsy needles is an extremely safe procedure with few associated minor and major complications. Those complications are summarized in Table 2.

Various factors such as indication for biopsy, operator experience, needle type, and number of passes can affect the rate of post biopsy complications. In the large Japanese cohort of 2,045 percutaneous native renal biopsies (Kamitsuji et al., 1999), the rate of gross hematuria was very low and comparable between patients in whom an automated biopsy needle was used compared to the older Vim-Silverman needle in which the cutting core was advanced manually $(2.7 \%$ vs. $3 \%)$. On the other hand, in a retrospective analysis of 177 percutaneous renal biopsies, Davis et al (Davis et el., 1998) noted a significantly higher rate of post-biopsy hematoma in those procedures performed with an automated biopsy needle (Meditech ASAP Automatic 15-G Core Biopsy System needle) compared to a non-automated device (14 G Franklin-Vim-Silverman needle or 15 G Trucut needle). However, the authors report the use of CT scan or ultrasound for post-biopsy imaging in the automated group compared to ultrasound only in the non-automated group, which might have led to increased detection of hematomas in the former because of CT's higher sensitivity, rather than actual difference related to the biopsy device. Simckes et al (Simckes et al., 2000) found a trend for the nonautomated Trucut needle to be the least traumatic compared to the modified Franklin-VimSilverman and automated spring-loaded needles in their cohort. In comparison, Webb et al (Webb et al., 1994) reported significantly more total complications with the Trucut needle compared to the automated biopsy needle, though the difference in major complications was not significant. Most likely, clinical factors and operator experience play a larger role in post-biopsy hematoma formation that the biopsy device itself.

\begin{tabular}{|c|c|}
\hline Minor complications & Major complications \\
\hline $\begin{array}{ll}\text { - } & \text { Microscopic hematuria } \\
\text { - } & \text { Self-limited gross hematuria } \\
\text { - } & \text { Asymptomatic peri-nephric hematoma } \\
\text { - } & \text { Asymptomatic decrease in } \mathrm{Hb} \\
\text { - } & \text { Sencentration } \\
\text { - } & \text { Mild painited arteriovenous fistula } \\
\text { - } & \text { Inadequate biopsy tissue and/ or } \\
& \text { failed biopsy }\end{array}$ & $\begin{array}{l}\text { - } \quad \text { Persistent gross hematuria } \\
\text { - } \quad \text { Symptomatic peri-nephric hematoma } \\
\text { - } \quad \text { Significant decrease in } \mathrm{Hb} \\
\text { concentration requiring blood } \\
\text { transfusion } \\
\text { - } \quad \text { Hypotension } \\
\text { - } \quad \text { Symptomatic arteriovenous fistula } \\
\text { - } \quad \text { Inadvertent damage to adjacent organs } \\
\text { - } \text { (e.g. liver, intestine) } \\
\text { - } \quad \text { Urinary tract infection } \\
\text { - } \quad \text { Urinary tract obstruction } \\
\text { - } \quad \text { Acute Renal Failure } \\
\text { - } \text { Allograft loss } \\
\text { - Nephrectomy } \\
\text { - } \quad \text { Death }\end{array}$ \\
\hline
\end{tabular}

Table 2. Complications Post-Renal Biopsy 
No difference has been reported in complication rates between using a 14-G Biopty gun needle or an automated 14-G Trucut needle, suggesting that needle size may influence the rate of complications more than needle type (Webb et al., 1994). Along those lines, Vidhun et al (Vidhun et al., 2003) have shown in renal allograft biopsies a higher incidence of perinephric hematoma ( $43 \%$ vs. $13.3 \%)$ and macroscopic hematuria ( $29 \%$ vs. $2.3 \%)$ with use of a 16-G versus an 18-G biopsy needle. Similar findings in native renal biopsies were also reported from a large Brazilian cohort (Piotto et al., 2008). As such, Birk et al (Birk et al., 2007) hypothesized that the slightly higher incidence of post-biopsy gross hematuria $(8.4 \%)$ in their cohort of 43 renal transplant recipients compared to previously published reports (1.9-3.5\%) was their use of a larger 16-G needle compared to an 18-G needle used elsewhere.

With regards to other factors, several retrospective analyses have shown no significant difference in complication rates whether the biopsy was performed as an outpatient or inpatient procedure (Hussain et al., 2003, 2010; Simckes et al., 2000), under general anesthesia or sedation (Durkan et al., 2006; Hussain et al., 2010; Webb et al., 1994), by a supervised trainee or by an attending physician or consultant (Durkan et al., 2006; Simckes et al., 2000), and between an intraperitoneal and extraperitoneal graft in the case of allograft percutaneous biopsies (Vidhun et al., 2003).

Interestingly, in native percutaneous biopsies, one author (Hussain et al., 2003) observed a trend for a higher incidence of gross hematuria post biopsy in those patients with a histological diagnosis of IgA Nephropathy/ Henoch-Schonlein Purpura. In the case of renal allografts, biopsies for urgent issues were noted to have a higher incidence of post biopsy hematoma compared to protocol biopsies (Vidhun et al., 2003). Increased number of passes was significantly associated with obtaining more adequate tissue for making a histological diagnosis (Durkan et al., 2006), but with a slightly increased but not significant trend towards hematoma formation (Simckes et al., 2000).

Through the decades, the safety of percutaneous renal biopsy has been verified in several large pediatric case series. Death is extremely rare. One early review (Al Rasheed et al., 1990, as cited in White, 1963) reported 17 deaths in more than 10,000 biopsies (0.17\%). Similarly, another large review at that time reported a mortality rate of $0.12 \%$ in 4000 biopsies (Simckes et al., 2000, as cited in Dodge et al., 1962). On the other hand, Edelmann found no deaths in a review of reports published between 1971-1976 of more than 1,700 percutaneous biopsies in children (Simckes et al., 2000, as cited in Edelmann et al., 1992). This improved safety profile continues to be reported in more recent series from North American and various institutions in Europe and Asia (Al Makdama \& Al-Akash, 2006; Birk et al., 2007; Hussain et al., 2010; Kersnik Levart et al., 2001; Mahajan et al., 2010) and likely is mediated by concomitant imaging at the time of biopsy decreasing the chances for catastrophic hemorrhage or damage to vital organs other than the kidney.

Given the use of different definitions and thresholds to report complications, it is worth noting, however, that rates of so-called minor and major complications post-biopsy are somewhat difficult to compare between individual centers. For example, one study included microscopic hematuria as a minor complication, a finding almost universally seen in all patients undergoing renal biopsy (Al Rasheed et al., 1990). Some studies include gross hematuria as a major complication, while others only include it if persistent and associated with hemodynamic instability and transfusion requirement. In their audit of UK centers, Hussain et al included 39 patients with gross hematuria in the major complication group 
while only 4 of them required blood transfusions (Hussain et al., 2010). Regardless of those differences, most recent series report "major" complication rates in the $0-5 \%$ range and "minor" complications rates in the $8-15 \%$ range, though most complications that are reported in either category are of little immediate or long-lasting clinical significance to the patient's well-being.

Similar low complication rates also can be found with allograft biopsies. Benfield et al (Benfield et al., 1999) reported data from 19 pediatric transplant centers on 86 children who underwent 212 allograft biopsies. There were a total of 9 complications (4.2\%) with only 4 (1.9\%) requiring intervention. No patient lost kidney function or required nephrectomy after graft biopsy. Vidhun et al (Vidhun et al., 2003) specifically analyzed complication rates in adult-sized renal allografts in children and reported an overall complication rate of $16.1 \%$, consisting mostly of perinephric hematomas $(13.4 \%)$, while the gross hematuria rate $(2.7 \%)$ was similar to the cohort reported by Benfield. Most of those hematomas (81.4\%) were small $(<1 \mathrm{~cm})$, and no patient in that cohort required intervention related to post-biopsy complications.

\section{Pathologic findings}

The ultimate goal of the renal biopsy is to obtain sufficient tissue to make a diagnosis or guide therapy. Based on histologic assessment of the biopsy samples, therapeutic intervention may be initiated or altered and important prognostic information may be gained.

It is crucial to obtain sufficient tissue to allow proper assessment by the pathologist. In certain pediatric renal diseases, light microscopy may be the most critical element, such as in the child with steroid resistant nephrotic syndrome in which the differential is minimal change disease versus focal and segmental glomerulosclerosis. In others, such as $\operatorname{IgA}$ nephropathy, immunofluorescence studies play a vital role and, in some, such as idiopathic membranoproliferative glomerulonephritis, electron microscopy will be necessary to supplement light microscopy and immunofluorescence results. Table Three summarizes the key pathologic studies to obtain on biopsy samples based on suspected clinical diagnosis. Table Four lists the histopathologic changes typically seen in several pediatric renal diseases.

\begin{tabular}{|c|c|c|c|}
\hline $\begin{array}{c}\text { Suspected or Known } \\
\text { Disease }\end{array}$ & $\begin{array}{c}\text { Light } \\
\text { Microscopy }\end{array}$ & Immunofluorescence & $\begin{array}{c}\text { Electron } \\
\text { Microscopy }\end{array}$ \\
\hline $\begin{array}{c}\text { IgA Nephropathy } \\
\text { Henoch-Schonlein } \\
\text { Purpura }\end{array}$ & $\begin{array}{c}\mathrm{X} \\
\text { Defines extent } \\
\text { and severity of } \\
\text { process }\end{array}$ & $\begin{array}{c}\text { Necessary for } \\
\text { diagnosis }\end{array}$ & $\begin{array}{c}\text { Suggested but not } \\
\text { required }\end{array}$ \\
\hline $\begin{array}{c}\text { Systemic Lupus } \\
\text { Erythematosus }\end{array}$ & $\begin{array}{c}\mathrm{X} \\
\text { Necessary to } \\
\text { identify } \\
\text { class/severity }\end{array}$ & $\mathrm{X}$ & $\begin{array}{c}\mathrm{X} \\
\text { Necessary to } \\
\text { diagnose Class V } \\
\text { (membranous) }\end{array}$ \\
\hline $\begin{array}{c}\text { Membranoproliferative } \\
\text { Glomerulonephritis }\end{array}$ & $\mathrm{X}$ & $\mathrm{X}$ & $\begin{array}{c}\mathrm{X} \\
\text { Necessary for } \\
\text { diagnosis }\end{array}$ \\
\hline
\end{tabular}




\begin{tabular}{|c|c|c|c|}
\hline $\begin{array}{c}\text { Thin Basement } \\
\text { Membrane Disease } \\
\text { Hereditary Nephritis } \\
\text { Alport's } \\
\text { Nail Patella Syndrome }\end{array}$ & $X$ & $X$ & $\begin{array}{c}\mathrm{X} \\
\text { Necessary for } \\
\text { diagnosis }\end{array}$ \\
\hline $\begin{array}{l}\text { Minimal Change } \\
\text { Nephrotic Syndrome } \\
\text { Focal and Segmental } \\
\text { Glomerulosclerosis }\end{array}$ & $X$ & $X$ & $x$ \\
\hline $\begin{array}{l}\text { ANCA associated } \\
\text { vasculitis } \\
\text { Anti-GBM disease } \\
\text { Rapidly progressive } \\
\text { glomerulonephritis }\end{array}$ & $\mathrm{X}$ & $X$ & $\begin{array}{l}\text { ? May not be } \\
\text { crucial }\end{array}$ \\
\hline Transplant Biopsies* & $X$ & $X * *$ & \\
\hline
\end{tabular}

*If suspected recurrent disease, see above disease categories for tissue processing recommendations.

** C4d crucial for diagnosis of acute antibody-mediated rejection

Table 3. Desired Pathology Studies Based on Suspected Diagnosis

\begin{tabular}{|c|c|c|c|}
\hline Disease & Light Microscopy & Immunofluorescence & Electron Microscopy \\
\hline \multicolumn{4}{|l|}{ Nephritis } \\
\hline IgA Nephropathy & $\begin{array}{l}\text { Focal or diffuse } \\
\text { mesangial } \\
\text { hypercellularity }\end{array}$ & Mesangial IgA deposits & $\begin{array}{l}\text { Focal mesangial } \\
\text { proliferation with } \\
\text { electron-dense } \\
\text { subendothelial deposits }\end{array}$ \\
\hline Henoch-Schonlein Purpura & $\begin{array}{l}\text { Focal or diffuse } \\
\text { mesangial } \\
\text { hypercellularity, } \pm \\
\text { crescents }\end{array}$ & Granular IgA & Immune deposits \\
\hline \multicolumn{4}{|l|}{$\begin{array}{l}\text { Systemic Lupus } \\
\text { Erythematosus }\end{array}$} \\
\hline I: Minimal Mesangial & Normal & $\begin{array}{l}\text { Mesangial immune } \\
\text { deposits (Ig, C3, C4) }\end{array}$ & Normal \\
\hline II: Mesangial Proliferative & $\begin{array}{l}\text { Increased mesangial } \\
\text { matrix }\end{array}$ & $\begin{array}{l}\text { Mesangial immune } \\
\text { deposits (Ig, C3, C4) }\end{array}$ & $\begin{array}{l}\text { Few or no subepithelial } \\
\text { or subendothelial } \\
\text { deposits }\end{array}$ \\
\hline III: Focal & $\begin{array}{l}\text { Less than } 50 \% \text { of } \\
\text { glomeruli involved }\end{array}$ & $\begin{array}{l}\text { Mesangial deposits, few } \\
\text { subepithelial and } \\
\text { subendothelial deposits } \\
(\mathrm{Ig}, \mathrm{C} 3, \mathrm{C} 4)\end{array}$ & $\begin{array}{l}\text { Focal, subendothelial } \\
\text { deposits }\end{array}$ \\
\hline IV: Diffuse & $\begin{array}{l}\text { Nearly all glomeruli } \\
\text { involved, wire-loop } \\
\text { appearance- } \\
\text { thickened BM }\end{array}$ & $\begin{array}{l}\text { Mesangial deposits, few } \\
\text { subepithelial and } \\
\text { subendothelial deposits } \\
(\mathrm{Ig}, \mathrm{C} 3, \mathrm{C} 4)\end{array}$ & $\begin{array}{l}\text { Endothelial cell } \\
\text { proliferation } \\
\text { Subendothelial immune } \\
\text { complex deposition }\end{array}$ \\
\hline
\end{tabular}




\begin{tabular}{|c|c|c|c|}
\hline V: Membranous & See membranous GN & Subepithelial Ig, C3, C4 & Subepithelial deposits \\
\hline VI: Advanced Sclerosing & $\begin{array}{l}\geq 90 \% \text { of glomeruli } \\
\text { globally sclerosed }\end{array}$ & & \\
\hline $\begin{array}{l}\text { Membranoproliferative } \\
\text { Glomerulonephritis Type I }\end{array}$ & $\begin{array}{l}\text { Mesangial and } \\
\text { endothelial cell } \\
\text { proliferation, } \\
\text { thickened basement } \\
\text { membrane due to } \\
\text { extensive immune } \\
\text { complex deposition, } \\
\text { increased mesangial } \\
\text { matrix } \\
\text { "Tram-track" or } \\
\text { double-contour } \\
\text { appearance of } \\
\text { basement membrane } \\
\text { (best seen with silver } \\
\text { stain) }\end{array}$ & Granular IgG and C3 & $\begin{array}{l}\text { Mesangial Proliferation } \\
\text { with immune deposits, } \\
\text { subendothelial electron } \\
\text { dense deposits between } \\
\text { layers of BM double } \\
\text { contours }\end{array}$ \\
\hline $\begin{array}{l}\text { Membranoproliferative } \\
\text { Glomerulonephritis Type II } \\
\text { (Dense Deposit Disease) }\end{array}$ & See MPGN Type I & $\begin{array}{l}\text { C3 linear or double- } \\
\text { contoured along BM }\end{array}$ & $\begin{array}{l}\text { Subepithelial deposits- } \\
\text { Electron dense deposits } \\
\text { in ribbon-like pattern }\end{array}$ \\
\hline $\begin{array}{l}\text { Thin Basement Membrane } \\
\text { Disease }\end{array}$ & Normal & Normal & Diffuse thinning of BM \\
\hline Alport's & $\begin{array}{l}\text { Early: Normal } \\
\text { Late: Sclerosis }\end{array}$ & Negative & $\begin{array}{l}\text { Split basement } \\
\text { membrane }\end{array}$ \\
\hline $\begin{array}{l}\text { Post-Infectious } \\
\text { Glomerulonephritis }\end{array}$ & $\begin{array}{l}\text { Enlarged glomeruli } \\
\text { Endocapillary } \\
\text { proliferation } \\
\text { Obliteration of } \\
\text { capillary loops } \\
\text { Increased mesangial } \\
\text { cells } \\
\text { “Exudative } \\
\text { proliferative GN” }\end{array}$ & \begin{tabular}{|l} 
Irregular granular C3, \\
IgG,
\end{tabular} & $\begin{array}{l}\text { Acute: subepithelial } \\
\text { humps, disappear by } 6^{\text {th }} \\
\text { week }\end{array}$ \\
\hline Interstitial Nephritis & $\begin{array}{l}\text { Cellular infiltrates in } \\
\text { interstitium }\end{array}$ & Negative & $\begin{array}{l}\text { Interrupted BM with } \\
\text { thickened areas }\end{array}$ \\
\hline Hemolytic Uremic Syndrome & $\begin{array}{l}\text { Thrombosis of } \\
\text { glomeruli, arterioles }\end{array}$ & Negative & No deposits \\
\hline \multicolumn{4}{|l|}{ Nephrotic Syndrome } \\
\hline $\begin{array}{l}\text { Minimal Change Nephrotic } \\
\text { Syndrome }\end{array}$ & Normal & Negative & $\begin{array}{l}\text { Marked foot process } \\
\text { effacement }\end{array}$ \\
\hline $\begin{array}{l}\text { Focal and Segmental } \\
\text { Glomerulosclerosis }\end{array}$ & $\begin{array}{l}\text { Segmental sclerosis } \\
\text { of glomeruli }\end{array}$ & $\begin{array}{l}\text { Negative (may be } \\
\text { positive for mesangial } \\
\text { C3, IgM) }\end{array}$ & $\begin{array}{l}\text { Foot process effacement, } \\
\text { early hyaline deposition }\end{array}$ \\
\hline Membranous Nephropathy & $\begin{array}{l}\text { All glomeruli } \\
\text { affected } \\
\text { Thickened capillary } \\
\text { walls } \\
\text { Membrane "spikes" }\end{array}$ & Granular IgG or C3 & $\begin{array}{l}\text { Thickened basement } \\
\text { membrane } \\
\text { Electron dense } \\
\text { subepithelial immune } \\
\text { deposits } \\
\text { Spikes }\end{array}$ \\
\hline
\end{tabular}




\begin{tabular}{|c|c|c|c|}
\hline $\begin{array}{l}\text { Rapidly Progressive } \\
\text { Glomerulonephritis }\end{array}$ & & & \\
\hline ANCA associated vasculitis & \begin{tabular}{|l|} 
Endocapillary \\
proliferation, some \\
mesangial \\
proliferation, urinary \\
space open, focal \\
necrosis, crescents \\
Proliferation of \\
podocytes and \\
epithelial cells, \\
proliferation of cells \\
around Bowman's \\
capsule leads to \\
crescent formation \\
\end{tabular} & \begin{tabular}{|l|} 
Negative \\
\\
\end{tabular} & No deposits \\
\hline Anti-GBM disease & \begin{tabular}{|l|} 
Endocapillary \\
proliferation, some \\
mesangial \\
proliferation, urinary \\
space open, focal \\
necrosis, crescents \\
Proliferation of \\
podocytes and \\
epithelial cells, \\
proliferation of cells \\
around Bowman's \\
capsule leads to \\
crescent formation
\end{tabular} & $\begin{array}{l}\text { Anti-glomerular } \\
\text { basement membrane } \\
\text { antibodies (IgG) } \\
\text { Linear pattern } \\
\end{array}$ & No deposits \\
\hline \multicolumn{4}{|l|}{ Transplant Biopsies } \\
\hline Acute Cellular Rejection & $\begin{array}{l}\text { Tubulitis } \\
\text { Endothelialitis }\end{array}$ & & \\
\hline Humoral Rejection & & C4d positive staining & \\
\hline Calcineurin Inhibitor Toxicity & $\begin{array}{l}\text { Concentric } \\
\text { hyalinosis } \\
\text { Interstitial Fibrosis }\end{array}$ & + Arteriolar IgM & $\begin{array}{l}\text { Necrosis, smooth } \\
\text { muscle cell injury }\end{array}$ \\
\hline
\end{tabular}

Table 4. Histopathology Based on Diagnosis and Type of Tissue Study

\section{Conclusion}

Renal biopsy in children is a safe procedure, typically performed percutaneously with ultrasound guidance and conscious sedation, and with an 8 to 24 hour period of post-procedure observation. Biopsy allows diagnosis of new renal conditions, assesses health of the renal parenchyma by defining the extent of injury and potential for recovery, and provides the pediatric clinician with valuable information to tailor further diagnostic or therapeutic interventions. Surgical renal biopsy by open technique or laparoscopic approach is less commonly required for the child with an isolated renal condition. The ability to rely on percutaneous biopsy simplifies the typical procedure, decreases patient time spent hospitalized or under supervised observation, and ultimately provides economy of health care costs. More importantly, by allowing 
for precise histopathologic diagnosis rather than clinical assessment alone, the use of renal biopsy as needed in children helps to expand the understanding of the impact and course of certain pediatric renal diseases, their response to therapy, and their prognosis.

\section{References}

Al Makdama, A., and S. Al-Akash. 2006. Safety of percutaneous renal biopsy as an outpatient procedure in pediatric patients. Ann Saudi Med 26 (4):303-5.

al Rasheed, S. A., M. M. al Mugeiren, M. B. Abdurrahman, and A. T. Elidrissy. 1990. The outcome of percutaneous renal biopsy in children: an analysis of 120 consecutive cases. Pediatr Nephrol 4 (6):600-3.

Anderson, S. E., and R. C. Whitaker. 2009. Prevalence of obesity among US preschool children in different racial and ethnic groups. Arch Pediatr Adolesc Med 163 (4):344-8.

Benfield, M. R., J. Herrin, L. Feld, S. Rose, D. Stablein, and A. Tejani. 1999. Safety of kidney biopsy in pediatric transplantation: a report of the Controlled Clinical Trials in Pediatric Transplantation Trial of Induction Therapy Study Group. Transplantation 67 (4):544-7.

Birk, P. E., T. D. Blydt-Hansen, A. B. Dart, L. M. Kaita, C. Proulx, and G. Taylor. 2007. Low incidence of adverse events in outpatient pediatric renal allograft biopsies. Pediatr Transplant 11 (2):196-200.

Broyles, S., P. T. Katzmarzyk, S. R. Srinivasan, W. Chen, C. Bouchard, D. S. Freedman, and G. S. Berenson. 2010. The pediatric obesity epidemic continues unabated in Bogalusa, Louisiana. Pediatrics 125 (5):900-5.

Caione, P., S. Micali, S. Rinaldi, N. Capozza, A. Lais, E. Matarazzo, G. Maturo, and F. Micali. 2000. Retroperitoneal laparoscopy for renal biopsy in children. J Urol 164 (3 Pt 2):1080-2; discussion 1083.

Castoldi, M. C., R. M. Del Moro, M. L. D'Urbano, F. Ferrario, M. T. Porri, P. Maldifassi, G. D'Amico, and F. Casolo. 1994. Sonography after renal biopsy: assessment of its role in 230 consecutive cases. Abdom Imaging 19 (1):72-7.

Chesney, D. S., B. H. Brouhard, and R. J. Cunningham. 1996. Safety and cost effectiveness of pediatric percutaneous renal biopsy. Pediatr Nephrol 10 (4):493-5.

Cravero, J. P., G. T. Blike, M. Beach, S. M. Gallagher, J. H. Hertzog, J. E. Havidich, and B. Gelman. 2006. Incidence and nature of adverse events during pediatric sedation/anesthesia for procedures outside the operating room: report from the Pediatric Sedation Research Consortium. Pediatrics 118 (3):1087-96.

Davis, I. D., W. Oehlenschlager, M. A. O'Riordan, and E. D. Avner. 1998. Pediatric renal biopsy: should this procedure be performed in an outpatient setting? Pediatr Nephrol 12 (2):96-100.

Durkan, A. M., T. J. Beattie, A. Howatson, J. H. McColl, and I. J. Ramage. 2006. Renal transplant biopsy specimen adequacy in a paediatric population. Pediatr Nephrol $21(2): 265-9$. 
Fowler, S. M., V. Kon, L. Ma, W. O. Richards, A. B. Fogo, and T. E. Hunley. 2009. Obesityrelated focal and segmental glomerulosclerosis: normalization of proteinuria in an adolescent after bariatric surgery. Pediatr Nephrol 24 (4):851-5.

Hussain, F., M. Mallik, S. D. Marks, and A. R. Watson. 2010. Renal biopsies in children: current practice and audit of outcomes. Nephrol Dial Transplant 25 (2):485-9.

Hussain, F., A. R. Watson, J. Hayes, and J. Evans. 2003. Standards for renal biopsies: comparison of inpatient and day care procedures. Pediatr Nephrol 18 (1):53-6.

Kamitsuji, H., K. Yoshioka, and H. Ito. 1999. Percutaneous renal biopsy in children: survey of pediatric nephrologists in Japan. Pediatr Nephrol 13 (8):693-6.

Kersnik Levart, T., A. Kenig, J. Buturovic Ponikvar, D. Ferluga, M. Avgustin Cavic, and R. B. Kenda. 2001. Real-time ultrasound-guided renal biopsy with a biopsy gun in children: safety and efficacy. Acta Paediatr 90 (12):1394-7.

Lau, K. K., G. L. Berg, and L. Butani. 2009. Financial implications of pediatric outpatient renal biopsies: a single-center experience. J Nephrol 22 (1):69-74.

Luque Mialdea, R., R. Martin-Crespo Izquierdo, L. Diaz, A. Fernandez, D. Morales, and J. Cebrian. 2006. [Renal biopsy through a retroperitoneoscopic approach: our experience in 53 pediatric patients]. Arch Esp Urol 59 (8):799-803.

Mahajan, V., D. Suri, A. Saxena, and R. Nada. 2010. Should ultrasound guided percutaneous renal biopsy in children be done in a day care setting? Indian J Nephrol 20 (1): 21-4.

Mason, K. P., H. Padua, P. J. Fontaine, and D. Zurakowski. 2009. Radiologist-supervised ketamine sedation for solid organ biopsies in children and adolescents. AJR Am J Roentgenol 192 (5):1261-5.

Mendelssohn, D. C., and E. H. Cole. 1995. Outcomes of percutaneous kidney biopsy, including those of solitary native kidneys. Am J Kidney Dis 26 (4):580-5.

Mukhtar, Z., H. Steinbrecher, R. D. Gilbert, and P. V. Deshpande. 2005. Laparoscopic renal biopsy in obese children. Pediatr Nephrol 20 (4):495-8.

Ogborn, M. R., and P. C. Grimm. 1992. Pediatric renal biopsy in the ambulatory care environment. Pediatr Nephrol 6 (3):311-2.

Piotto, G. H., M. C. Moraes, D. M. Malheiros, L. B. Saldanha, and V. H. Koch. 2008. Percutaneous ultrasound-guided renal biopsy in children - safety, efficacy, indications and renal pathology findings: 14-year Brazilian university hospital experience. Clin Nephrol 69 (6):417-24.

Simckes, A. M., D. L. Blowey, K. M. Gyves, and U. S. Alon. 2000. Success and safety of sameday kidney biopsy in children and adolescents. Pediatr Nephrol 14 (10-11): 946-52.

Sweeney, C., D. F. Geary, D. Hebert, L. Robinson, and V. Langlois. 2006. Outpatient pediatric renal transplant biopsy--is it safe? Pediatr Transplant 10 (2):159-61.

Vidhun, J., J. Masciandro, L. Varich, O. Salvatierra, Jr., and M. Sarwal. 2003. Safety and risk stratification of percutaneous biopsies of adult-sized renal allografts in infant and older pediatric recipients. Transplantation 76 (3):552-7.

Webb, N. J., J. K. Pereira, P. G. Chait, and D. F. Geary. 1994. Renal biopsy in children: comparison of two techniques. Pediatr Nephrol 8 (4):486-8. 
Whittier, W. L., and S. M. Korbet. 2004. Timing of complications in percutaneous renal biopsy. J Am Soc Nephrol 15 (1):142-7. 


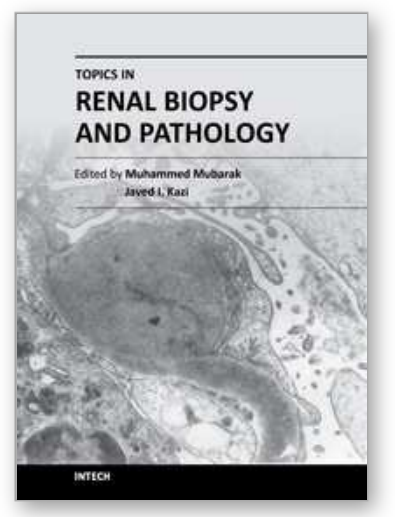

\author{
Topics in Renal Biopsy and Pathology \\ Edited by Dr. Muhammed Mubarak
}

ISBN 978-953-51-0477-3

Hard cover, 284 pages

Publisher InTech

Published online 04, April, 2012

Published in print edition April, 2012

There is no dearth of high-quality books on renal biopsy and pathology in the market. These are either single author or multi-author books, written by world authorities in their respective areas, mostly from the developed world. The vast scholarly potential of authors in the developing countries remains underutilized. Most of the books share the classical monotony of the topics or subjects covered in the book. The current book is a unique adventure in that it bears a truly international outlook and incorporates a variety of topics, which make the book a very interesting project. The authors of the present book hail not only from the developed world, but also many developing countries. The authors belong not only to US but also to Europe as well as to Pakistan and Japan. The scientific content of the book is equally varied, spanning the spectrum of technical issues of biopsy procurement, to pathological examination, to individual disease entities, renal graft pathology, pathophysiology of renal disorders, to practice guidelines.

\title{
How to reference
}

In order to correctly reference this scholarly work, feel free to copy and paste the following:

Isa F. Ashoor, Deborah R. Stein and Michael J. G. Somers (2012). Renal Biopsy in the Pediatric Patient, Topics in Renal Biopsy and Pathology, Dr. Muhammed Mubarak (Ed.), ISBN: 978-953-51-0477-3, InTech, Available from: http://www.intechopen.com/books/topics-in-renal-biopsy-and-pathology/pediatric-renal-biopsy

\section{INTECH}

open science | open minds

\author{
InTech Europe \\ University Campus STeP Ri \\ Slavka Krautzeka 83/A \\ 51000 Rijeka, Croatia \\ Phone: +385 (51) 770447 \\ Fax: +385 (51) 686166 \\ www.intechopen.com
}

\author{
InTech China \\ Unit 405, Office Block, Hotel Equatorial Shanghai \\ No.65, Yan An Road (West), Shanghai, 200040, China \\ 中国上海市延安西路65号上海国际贵都大饭店办公楼405单元 \\ Phone: +86-21-62489820 \\ Fax: $+86-21-62489821$
}


(C) 2012 The Author(s). Licensee IntechOpen. This is an open access article distributed under the terms of the Creative Commons Attribution 3.0 License, which permits unrestricted use, distribution, and reproduction in any medium, provided the original work is properly cited. 